\title{
A Dual-Band Printed End-Fire Antenna with DSPSL Feeding
}

\author{
Daofeng Ye, ${ }^{1,2}$ Yuanxin Li, ${ }^{1,2}$ Zhixi Liang, ${ }^{1,2}$ and Yunliang Long ${ }^{1,2}$ \\ ${ }^{1}$ Department of Electronics and Communication Engineering, Sun Yat-sen University, Guangzhou 510275, China \\ ${ }^{2}$ SYSU-CMU Shunde International Joint Research Institute, Shunde 528300, China \\ Correspondence should be addressed to Yuanxin Li; liyuanx@mail.sysu.edu.cn
}

Received 17 December 2015; Revised 28 April 2016; Accepted 9 May 2016

Academic Editor: N. Nasimuddin

Copyright (C) 2016 Daofeng Ye et al. This is an open access article distributed under the Creative Commons Attribution License, which permits unrestricted use, distribution, and reproduction in any medium, provided the original work is properly cited.

\begin{abstract}
A novel dual-band printed end-fired antenna with double-sided parallel-strip line (DSPSL) feeding is presented. The DSPSL acts in wideband transition using balanced transmission. Two different modes of the parasitic patches allow the antenna to work in different bands. The printed antenna is designed as a quasi-Yagi structure to achieve directivity in the lower band, and the parallel rectangular patches serve as the parasitic director. These patches act as radiation patches with end-fire direction characteristics in the upper band. The measured bandwidths were $18.3 \%$ for the lower frequency band $(2.28-2.74 \mathrm{GHz})$ and $12.6 \%$ for the upper frequency band $(5.46-6.2 \mathrm{GHz})$
\end{abstract}

\section{Introduction}

Owing to excellent characteristics including a low profile, simple structure, and low cost, printed end-fire antenna has been widely studied and used in many applications. Microstrip-fed quasi-Yagi antenna [1] is a conventional printed antenna. To increase its bandwidth, it changes its transmission structure [2]. Another approach used a wideband quasi-Yagi antenna with a microstrip-to-slotline as its balun [3]. Another application used an I-shape resonator to obtain a gain enhancement of about 4-6 dB [4].

Because of more diverse applications required for mobile wireless communication, some antennas for those devices require not only broad-band capabilities but the dual-band property. A conventional approach to achieve dual-band activity is using branch structure. In [5], the antenna with a simple branch structure allowed nonfixed base station backhaul in GSM communication. A printed antenna [6] for dual-band operations of L1-band Global Navigation Satellite System (GNSS) and S-band China Mobile Multimedia Broadcasting $(\mathrm{CMMB})$ was realized by using a meandered driven dipole and a concave parabolic reflector, and an analogous dual-band quasi-Yagi Wi-Fi antenna was proposed in [7]. Another method was used for a proposed dual-band quasiYagi antenna [8] based on application of split ring resonators (SRRs) to provide dual-mode, but this device had a narrow bandwidth due to the limited transmission structure. The use of double-sided parallel-strip line (DSPSL) has potential to overcome this problem. Due to its balance structure, more freedom can be provided in the microwave circuit design. In the past, most studies of DSPSL focused on the microwave circuit design, such as the ultrawide band balun and the low-pass filter $[9,10]$. Additional characterization and optimization of DSPSL have led to its wide application in the design of antenna performance $[11,12]$.

In this paper, a new dual-band printed end-fired antenna is presented. The antenna is fed by DSPSL to achieve two operation bands. Two modes of this printed antenna allow function with dual-band characteristic. In different operating bands, the proposed antenna uses parallel rectangular patches either as a director element or as radiation patches, and the driver dipole alternatively acts as the radiation part or feeding part. The lower band $(2.28-2.74 \mathrm{GHz})$ is centred at $2.4 \mathrm{GHz}$ and its upper band $(5.46-6.2 \mathrm{GHz})$ is centred at $5.8 \mathrm{GHz}$.

\section{Antenna Design}

Figure 1 shows the layout of the proposed dual-band printed end-fired antenna. Each side of the antenna is symmetrical, with an arm of driver dipole, the DSPSL, a parallel rectangular patch, and a bent reflector. Figure 2 shows the top side of the proposed antenna. In order to operate in dual-band, 


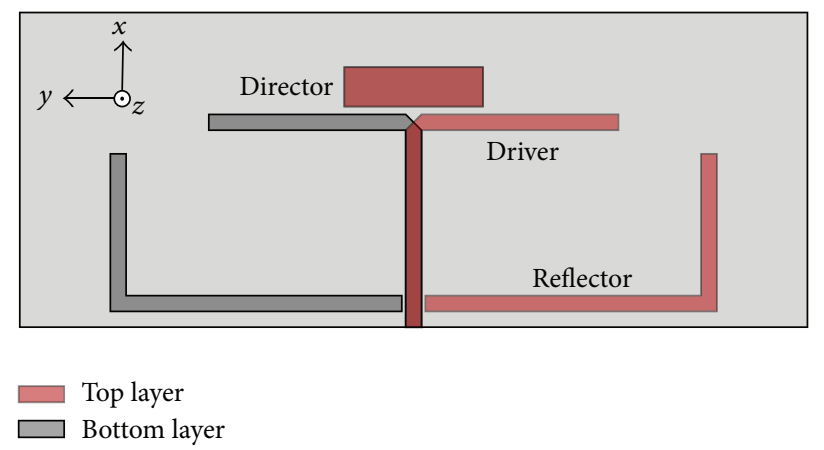

FIgURE 1: A dual-band printed end-fire antenna geometry.

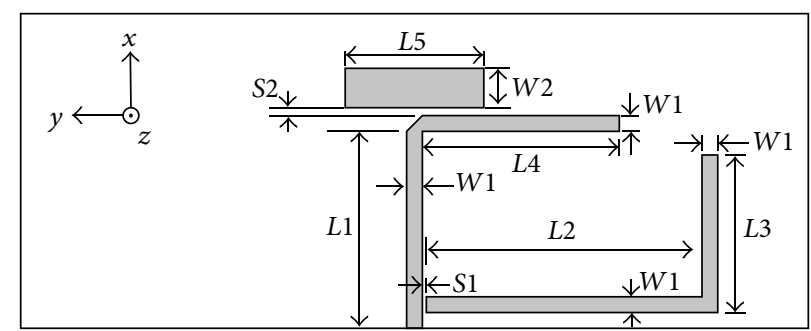

FiguRE 2: Dimensions of proposed dual-band printed end-fired antenna's top side.

TABLE 1: Parameter of the proposed antenna.

\begin{tabular}{lccccccccc}
\hline Symbol & $L 1$ & $L 2$ & $L 3$ & $L 4$ & $L 5$ & $W 1$ & $W 2$ & $S 1$ & $S 2$ \\
\hline Size $(\mathrm{mm})$ & 25 & 35 & 20 & 25.35 & 17.6 & 2 & 5 & 0.5 & 1 \\
\hline
\end{tabular}

the parallel rectangular patches are positioned on the top plane in place of the conventional parasitic dipole, allowing two independent modes, parasitic mode and radiation mode. The DSPSL acts as the feeding structure because it can provide balanced current at any frequency and broaden the bandwidth. Overall, the structure is simple. The reflector dipole is bent and its overall length is about twice the length of the driver dipole. The difference in the arms of the reflector allows changing the directivity of the two operating frequencies. The parameters of the proposed antenna are shown in Table 1.

All the patches, including the driver dipole, the parallel rectangular patches, the periodic offset DSPSL structure, and the bent reflectors, are printed on a Wangling Teflon woven glass fabric substrate with relative dielectric constant of $\varepsilon_{r}=$ 2.65, the dielectric loss tangent of $\tan \theta=0.0015$, and the thickness of $h=0.8 \mathrm{~mm}$. In the traditional design, the length of the driver dipole $(2 \times L 4)$ is approximately a half wavelength $(\lambda / 2)$ and about twice the length of the DSPSL $(L 1)$. To achieve a good match between the DSPSL and the driver, the widths of them are the same.

\section{Antenna Analysis}

Due to the opposite current direction in DSPSL, the transmission structure has no electromagnetic wave radiation and, compared with the antenna presented in [8], the current directions of the double arms of the dipole are the same to ensure end-fire direction without offset. The characteristic impendence of DSPSL is calculated with the modified ratio of the patch's width to the thickness of the substrate in [11]; that is,

$$
Z_{0}=\frac{120 \pi}{\sqrt{\varepsilon_{\text {eff }}}[W+1.393+0.667 \ln (W+1.444)]},
$$

where $\varepsilon_{\text {eff }}$ is the effective dielectric constant of the substrate. The suitable expression of $\varepsilon_{\text {eff }}$ is

$$
\varepsilon_{\mathrm{eff}}=\frac{\varepsilon_{r}+1}{2}+\frac{\varepsilon_{r}-1}{2} \frac{1}{\sqrt{1+10 / W}}
$$

where $\varepsilon_{r}$ is the relative dielectric constant of the substrate. $W$ is the modified ratio. For the nonoffset DSPSL,

$$
W=\frac{T}{h}-1,
$$

where $T$ is the width of the patch and $h$ is the thickness of the substrate in the DSPSL.

According to (2), the characteristic impendence of this DSPSL is about $50 \Omega$. The bandwidth is wider compared to the conventional printed quasi-Yagi antenna because of its balanced transmission structure.

The $E$-field magnitudes of two operating frequency are shown in Figure 3, and they are obviously different. This difference results from two different modes of the parallel rectangular patches, a director mode and a radiation mode. In Figure 3(a), the proposed antenna is a traditional quasiYagi antenna, and the electric field distributed in the dipole is apparently stronger than the rectangular patch at $2.4 \mathrm{GHz}$. The radiation of the antenna is mostly generated by the 


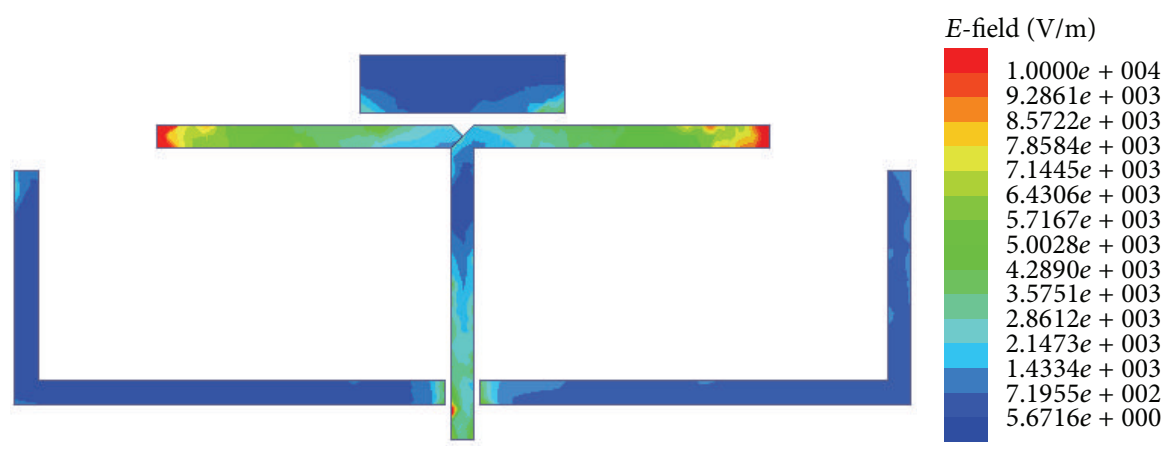

(a)
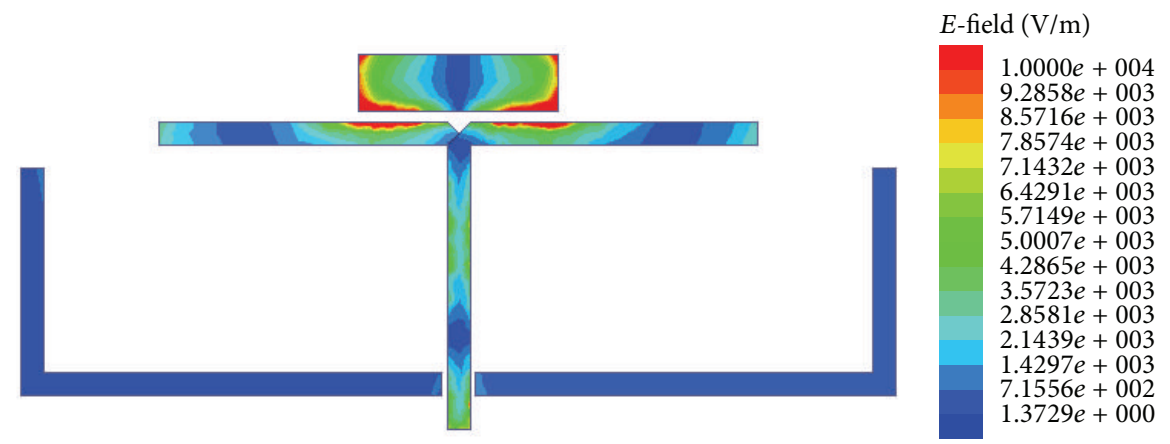

(b)

Figure 3: E-field magnitude of the antenna at (a) $2.4 \mathrm{GHz}$ and (b) $5.8 \mathrm{GHz}$.

driver dipole and the parallel rectangular patches operate in parasitic mode to act as a conventional parasitic director element, identical to the mechanism of the traditional print quasi-Yagi antenna.

When antenna resonates at $5.8 \mathrm{GHz}$ in Figure 3(b), the power mainly radiates out from the parallel rectangular patches. The $E$-field magnitude of the edge of rectangular patches as well as the part of the dipole that is located below the rectangular patches is stronger. The driver dipole has an alternative mode of operation in this operation band and acts in feeding, not as radiation parts. In this condition, the dipole of the antenna forces a time-varying magnetic field in the axial direction of the rectangular patches, thus forcing the parallel rectangular patches to resonate at $5.8 \mathrm{GHz}$. This reveals that the parallel rectangular patches are in radiation mode and behave like a radiation source at high frequency.

In this situation, two frequencies are generated independently of each other. The frequencies are easily controlled by changing the length of the dipole and the patches, the length of the dipole is approximately a half wavelength of the lower frequency, and the patches have the same length of about half the wavelength of the upper frequency. The $S$-parameter $(S 11)$ of the antennas with different lengths of the dipole and the patches are shown in Figure 4 and they can work separately in the GMS band and GNSS band.

\section{Measured Result}

A dual-band printed end-fire antenna was fabricated and is shown in Figure 5. The $S 11$ results of the proposed antenna

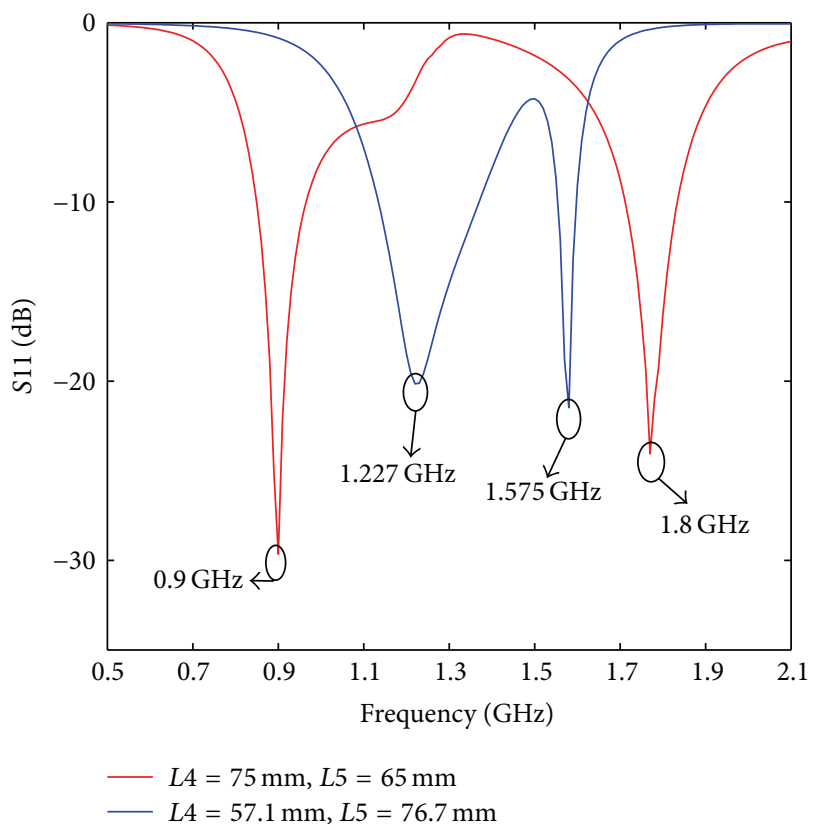

FIGURE 4: The simulated $S 11$ with different lengths of the dipole and the patches.

were measured and are shown in Figure 6. The proposed antenna works at two bands: a low operating frequency of $2.4 \mathrm{GHz}$ with $18.3 \%$ bandwidth which is provided from $2.28 \mathrm{GHz}$ to $2.74 \mathrm{GHz}$ and an upper operating frequency of 


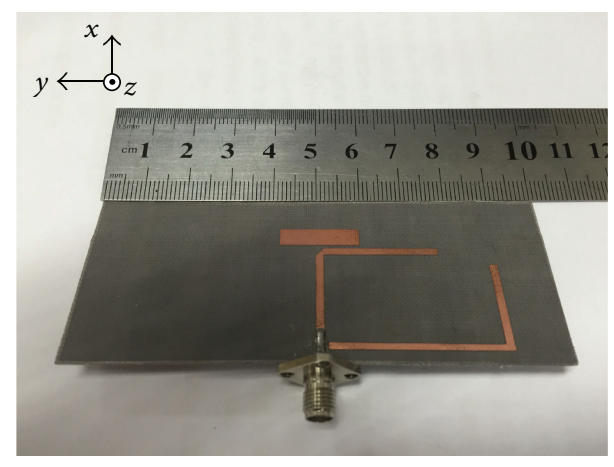

(a) Top layer

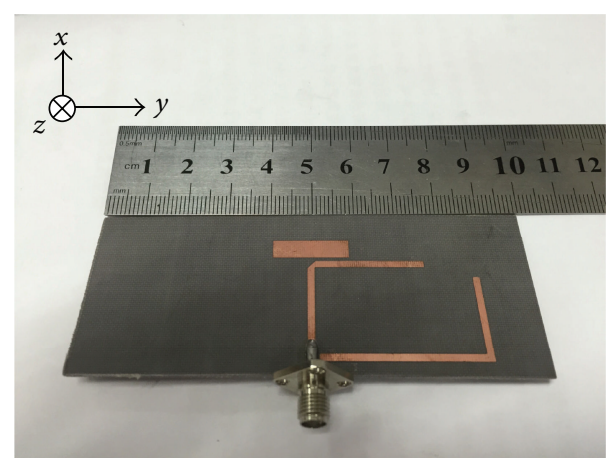

(b) Bottom layer

Figure 5: Fabricated dual-band printed end-fired antenna.

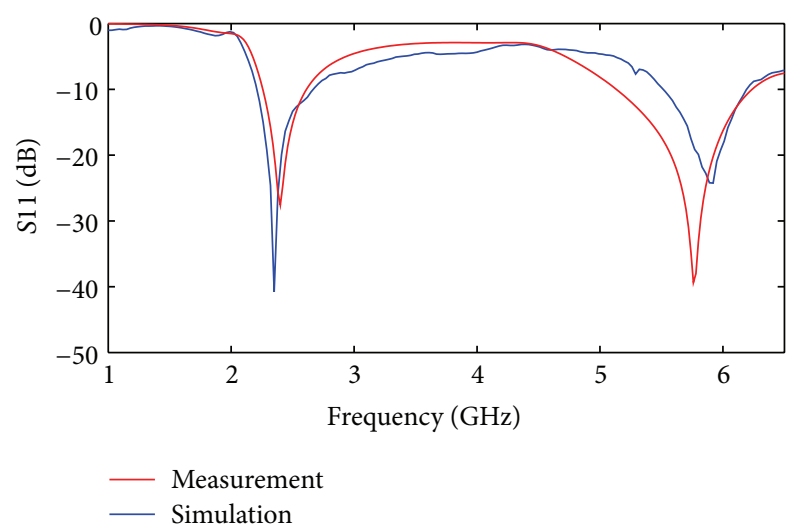

FIGURE 6: Measured and simulated $S 11$ for the antenna.

$5.8 \mathrm{GHz}$ that is generated by the radiation mode of the parallel rectangular patches, with a bandwidth of about $12.6 \%$.

The far-field radiation patterns are measured and shown in Figure 7. End-fire radiation patterns were detected in the $x-y$ and the $x-z$ planes at two frequencies. The main lobe of the antenna points to the $+x$ direction. Figure 8 shows the gains and efficiencies of the dual-bands. In different bands, the peak gain of the proposed antenna was about $5.2 \mathrm{~dB}$. The measured total efficiency was $83 \% \sim 95 \%$ from $2.2 \mathrm{GHz}$ to $2.8 \mathrm{GHz}$ and $84 \% \sim 98 \%$ from $5.4 \mathrm{GHz}$ to $6.3 \mathrm{GHz}$.

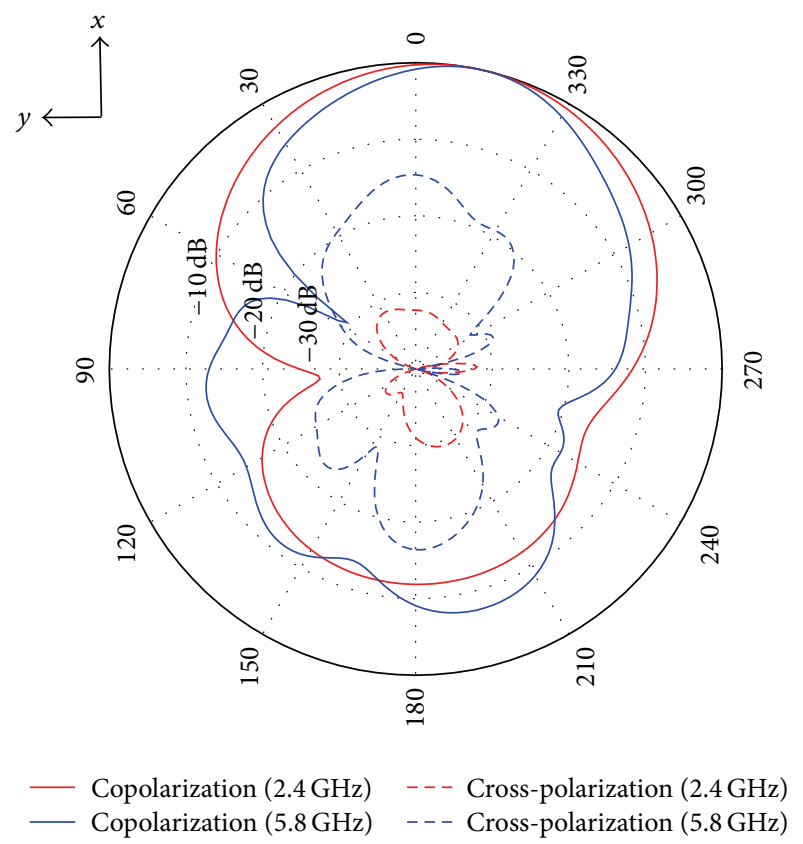

(a)

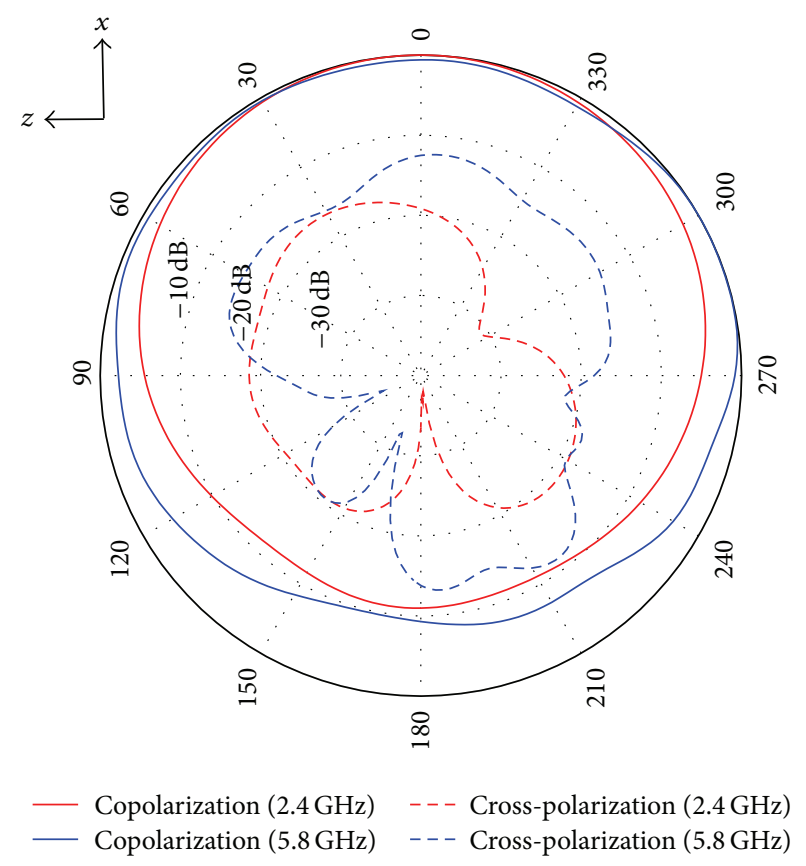

(b)

FIGURE 7: Measured radiation pattern of the antenna in (a) $x-y$ plane and (b) $x$ - $z$ plane.

\section{Conclusion}

A dual-band printed end-fired antenna with DSPSL feeding is presented. The proposed antenna has dual-band capacity resulting from substitution of the conventional director of the linear parasitic element with parallel rectangular patches. The application of the DSPSL easily simplifies the transmission structure. This antenna has a simple structure and will 


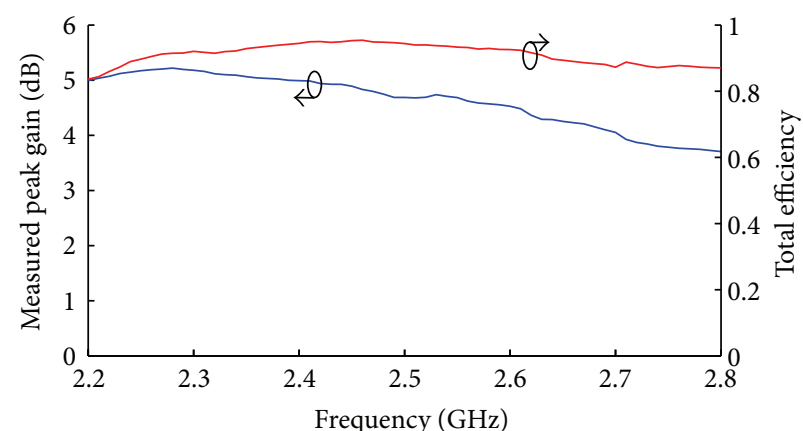

(a)

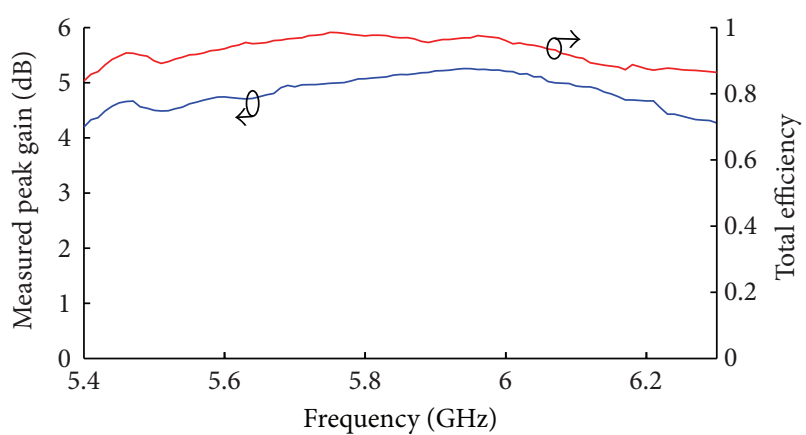

(b)

FIGURE 8: Gain and efficiency of (a) lower operating band and (b) upper operating band.

be useful in the applications of personal communication systems, such as Wi-Fi system.

\section{Competing Interests}

The authors declare that they have no competing interests.

\section{Acknowledgments}

This work was supported by Nature Science Foundation of Guangdong Province under Grant 2015A030312010.

\section{References}

[1] Y. Qian, W. R. Deal, N. Kaneda, and T. Itoh, "Microstrip-fed quasi-Yagi antenna with broadband characteristics," Electronics Letters, vol. 34, no. 23, pp. 2194-2196, 1998.

[2] N. Kaneda, W. R. Deal, Y. Qian, R. Waterhouse, and T. Itoh, "A broad-band planar quasi-Yagi antenna," IEEE Transactions on Antennas and Propagation, vol. 50, no. 8, pp. 1158-1160, 2002.

[3] P. T. Nguyen, A. Abbosh, and S. Crozier, "Wideband and compact quasi-Yagi antenna integrated with balun of microstrip to slotline transitions," Electronics Letters, vol. 49, no. 2, pp. 8889, 2013.

[4] Y. H. Sun, G. J. Wen, H. Y. Jin, P. Wang, and Y. J. Huang, "Gain enhancement for wide bandwidth endfire antenna with I-shaped resonator (ISR) structures," Electronics Letters, vol. 49, no. 12, pp. 736-737, 2013.

[5] Q. Xin, F. Zhang, B. Sun, Y. Zou, and Q. Liu, "A novel dual-band Yagi-Uda antenna for wireless communications," in Proceedings of the 9th International Symposium on Antennas Propagation and EM Theory (ISAPE '10), pp. 289-292, Guangzhou, China, November-December 2010.

[6] H.-C. Huang, J.-C. Lu, and P. Hsu, "A compact dual-band printed Yagi-Uda antenna for GNSS and CMMB applications," IEEE Transactions on Antennas and Propagation, vol. 63, no. 5, pp. 2342-2348, 2015.

[7] M. H. Hoang, H. P. Phan, T. Q. V. Hoang, and T.-P. Vuong, "Efficient compact dual-band antennas for GSM and Wi-Fi energy harvesting," in Proceedings of the 7th International Conference on Advanced Technologies for Communications (ATC '14), pp. 401-404, Hanoi, Vietnam, October 2014.
[8] D. O. Kim and C. Y. Kim, "Dual-band quasi-Yagi antenna with split ring resonator directors," Electronics Letters, vol. 48, no. 14, pp. 809-810, 2012.

[9] S. Sun and L. Zhu, "Stopband-enhanced and size-miniaturized low-pass filters using high-impedance property of offset finiteground microstrip line," IEEE Transactions on Microwave Theory and Techniques, vol. 53, no. 9, pp. 2844-2850, 2005.

[10] J.-X. Chen, J. L. Li, and Q. Xue, "Lowpass filter using offset double-sided parallel-strip lines," Electronics Letters, vol. 41, no. 24, pp. 1336-1337, 2005.

[11] Y. Li, Q. Xue, E. K.-N. Yung, and Y. Long, "The backfireto-broadside symmetrical beam-scanning periodic offset microstrip antenna," IEEE Transactions on Antennas and Propagation, vol. 58, no. 11, pp. 3499-3504, 2010.

[12] B. G. Duffley, G. A. Morin, M. Mikavica, and Y. M. M. Antar, "A wide-band printed double-sided dipole array," IEEE Transactions on Antennas and Propagation, vol. 52, no. 2, pp. 628-631, 2004. 


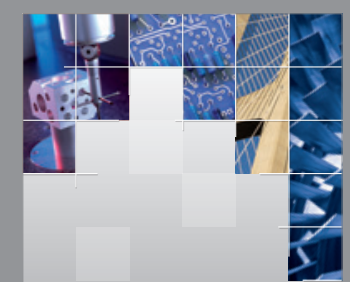

\section{Enfincering}
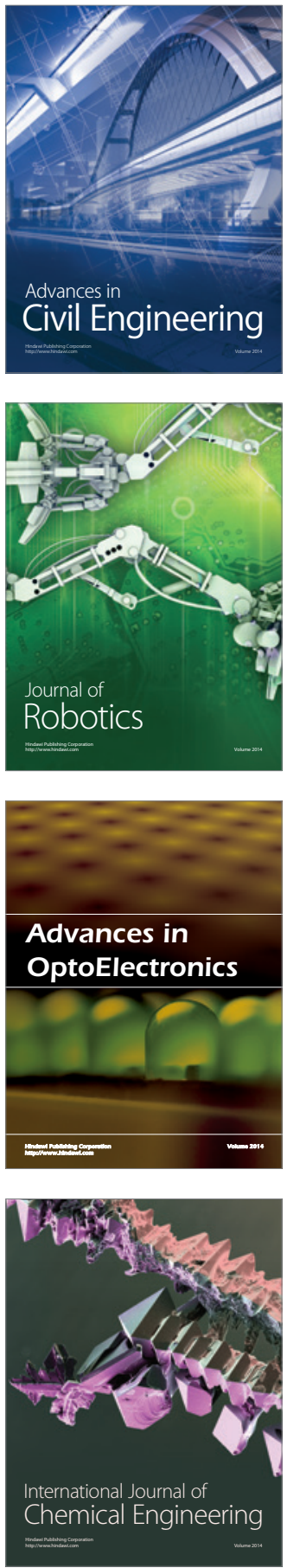

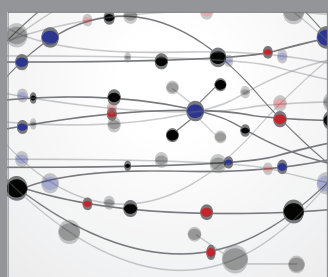

The Scientific World Journal

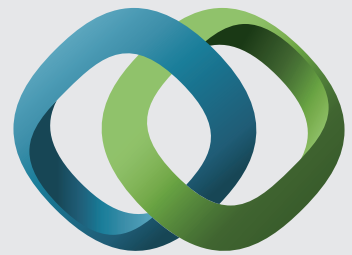

\section{Hindawi}

Submit your manuscripts at

http://www.hindawi.com
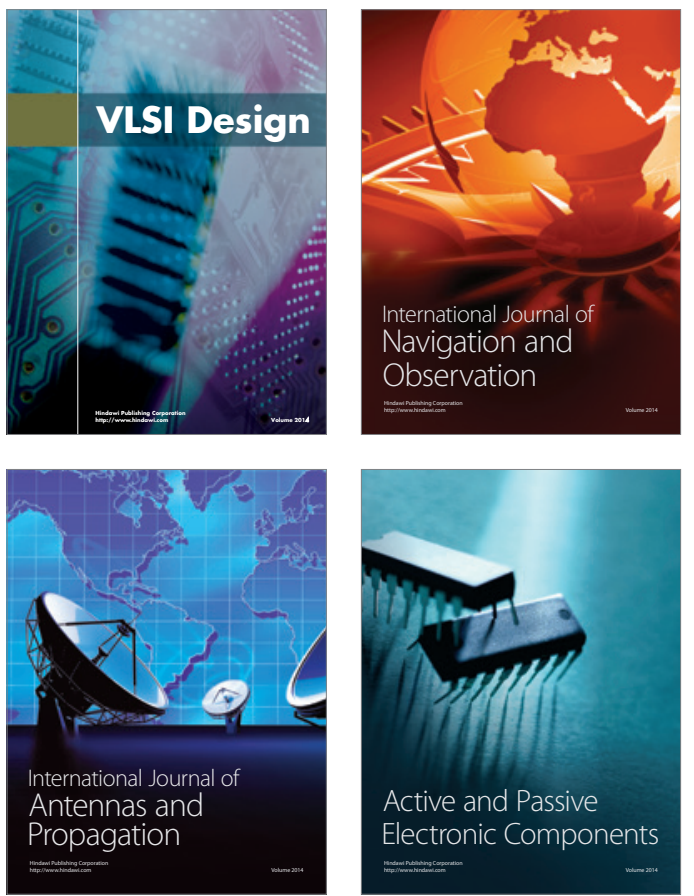
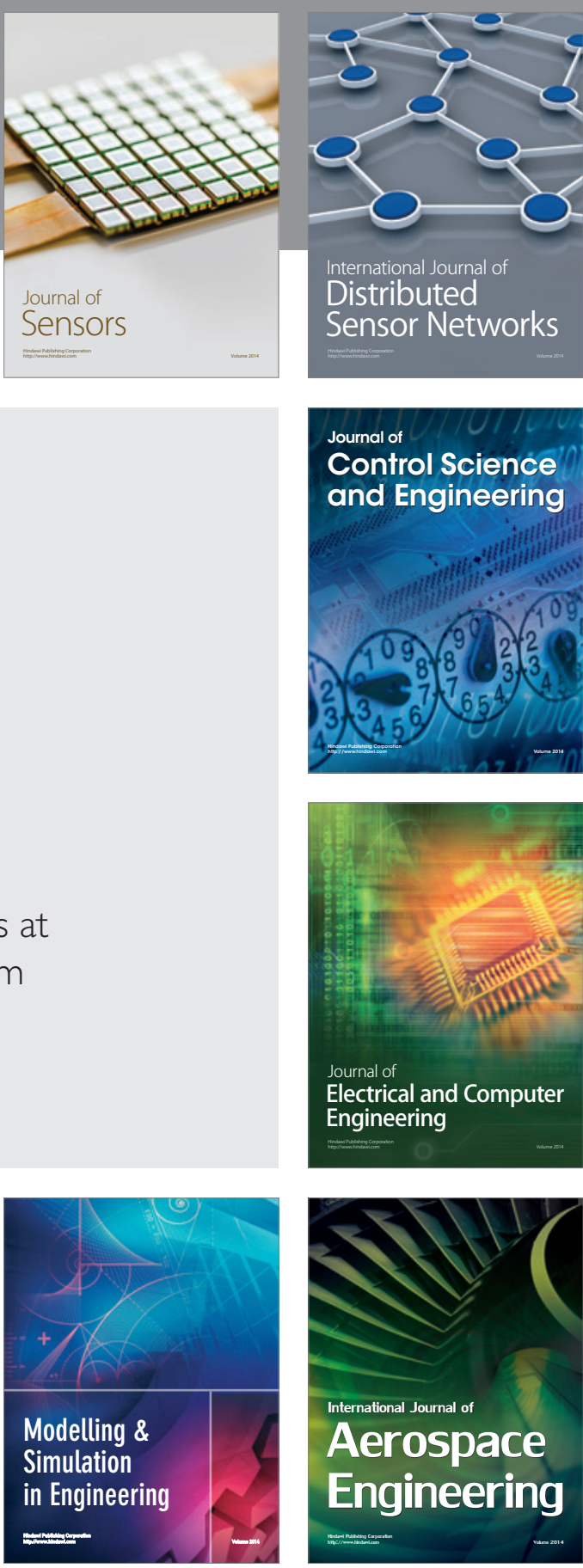

International Journal of

Distributed

Sensor Networks

Journal of

Control Science

and Engineering
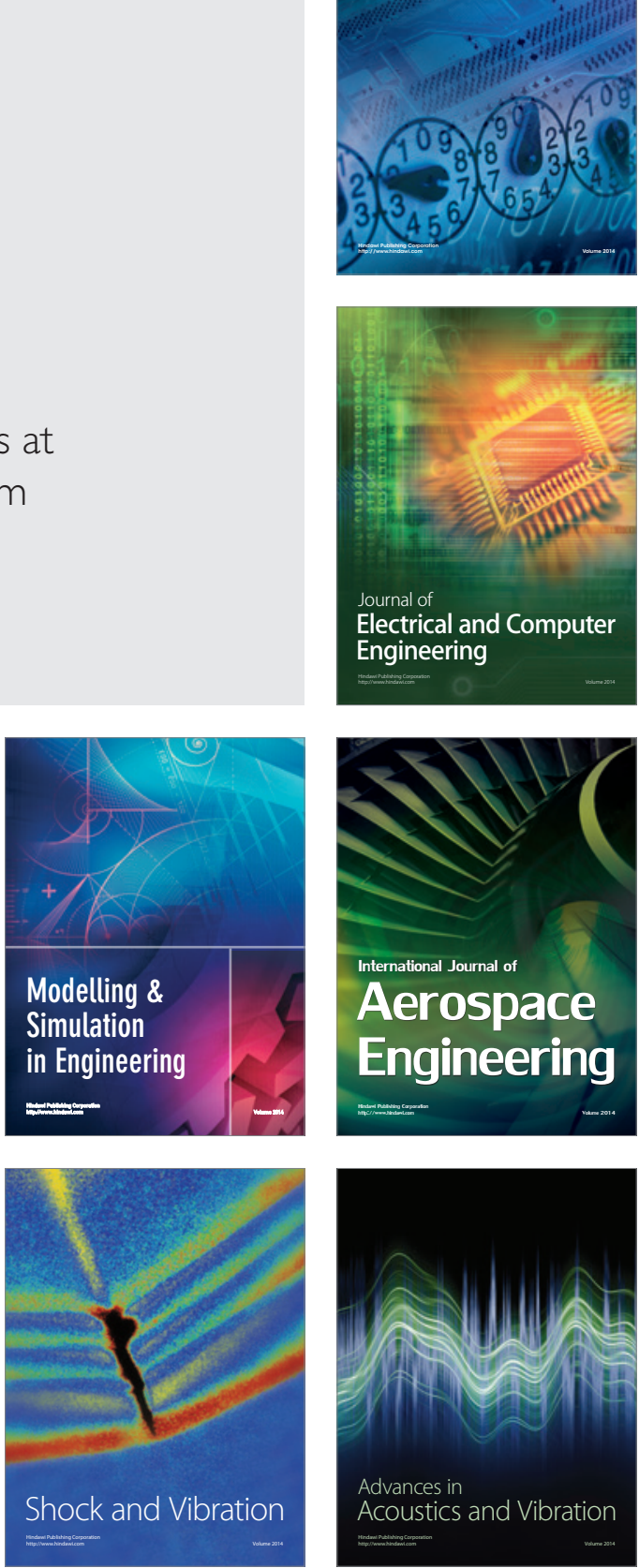